\title{
The Detection of Silver in Rain Water from Cloud Seeding Experiments in Australia
}

\author{
J. A. WARBURTON ${ }^{1}$ \\ Radiophysics Laboratory, CSIRO, Sydney, Australia \\ (Manuscript received 24 January 1963)
}

\begin{abstract}
ABSTRAC'T
A technique is being developed for detecting silver in very low concentrations in water. It is effective down to concentrations of $5 \times 10^{-12} \mathrm{gm} \mathrm{ml}^{-1}$.

The method involves collecting and concentrating the silver ions on an ion-exchange column, precipitating the silver collected as AgI and measuring its quantity by a cold-chamber method.

The performance of the system has been measured using the radio-isotope $\mathrm{Ag}^{110}$ in the form of aqueous soiutions of $\mathrm{AgNO}_{3}$. The column collects over 90 per cent of the silver ions from samples with concentrations greater than $10^{-11} \mathrm{gm} \mathrm{m}^{-1}$. For column loadings down to $10^{-7}$ gram, the elution efficiency, using a strong cation $\left(\mathrm{Ba}^{++}\right)$as the eluting substance, is greater than 20 per cent.

When the technique was used on samples of rainwater collected in the field, no silver was detected except when the rain fell from clouds which had been seeded with AgI.
\end{abstract}

\section{Introduction}

The detection of silver iodide in very low concentration in water is a problem which is of great interest to experimenters in the field of cloud-seeding. In Australia the seeding substance, silver iodide, is dispensed in fine particulate form from aircraft into the atmosphere, and its expected concentration in rainfall will be very much less than that detectable by normal chemical processes.

Isono $^{2}$ has recently reported a cold-chamber technique which is capable of detecting the presence of silver iodide in aqueous solutions of potassium iodide. He has shown that, provided the concentration of the AgI is in excess of about $10^{-10} \mathrm{gm} \mathrm{ml}^{-1}$, it can be detected as colloidal AgI which will nucleate ice crystals when sprayed into a super-cooled saturated atmosphere. If the AgI concentration is less than this value, as appears to be the case in two of the seeding areas of Australia, it becomes necessary to concentrate the AgI in some way before this very sensitive method of detection developed by Isono can be employed.

The present report describes a process, still under development, which concentrates the silver ions from the water samples. Details of the method and some preliminary results are presented. The method comprises: a) exhaustion of the $\mathrm{Ag}^{+}$ions from the solutions on to an ion exchange resin column; $b$ ) the removal in a concentrated solution of the $\mathrm{Ag}^{+}$ions from the resin, and c) the cold-chamber method of detection.

\footnotetext{
${ }^{1}$ Radiophysics Laboratory, C.S.I.R.O., University Grounds, Chippendale, N.S.W., Australia.

${ }^{2}$ Isono, Kenji, 1960: Private communication (July).
}

To determine the efficiencies of the ion-exchange process both in collecting the silver ions on, and eluting them from the resin at very low concentrations, small quantities of the radio-isotope $\mathrm{Ag}^{110}$ were passed as the nitrate in aqueous solution, through the columns. Measurements of concentration in this case were made with a sensitive scintillation counter.

Other means of detection of the small quantities of silver are available and a recent report by $\mathrm{McNutt}$ and Maier (1962) describes a somewhat similar piece of work in which a spectrophotometer was used to detect quantities down to $5 \times 10^{-8} \mathrm{gm}$ of silver eluted from an ion exchange column.

\section{Exhaustion of $\mathrm{Ag}^{+}$ions on to ion-exchange column}

The silver is extracted from the water sample by passing it through an ion-exchange column. The columns consist of three to six grams of a strong sulphonated polystyrene cation exchange resin in the hydrogen form. These resins have the property of exchanging their hydrogen for cations, the extent of exchange being specific to each ion (Bonner and Smith, 1957). A Röhm and Haas resin, Amberlite IR-120(H), has been used for most of the preliminary work. Its bead size was 50 mesh and the manufacturer stated that it is crosslinked with 8 per cent divinylbenzene. The exchange capacity of this resin is quoted as 4.5 milliequivalents per gram of resin. This means that each gram of resin will exchange 4.5 milligramequivalents of other cations for its exchangeable hydrogen. A number of other resins are now being tested for optimum mesh size and cross- 


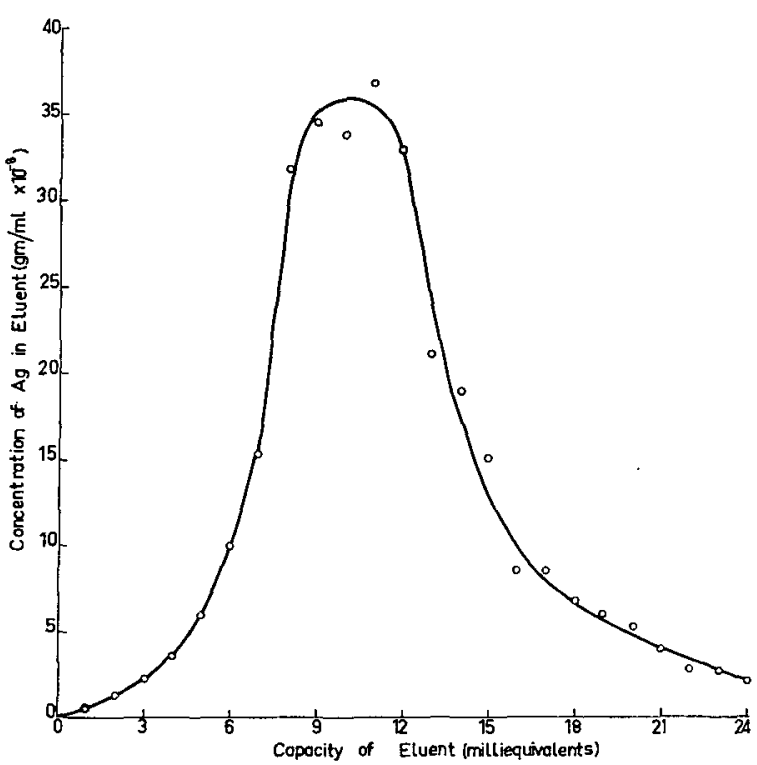

FIG. 1. Elution of $\mathrm{Ag}^{+110}$ with $0.05 \mathrm{M} \mathrm{Ba}\left(\mathrm{NO}_{3}\right)_{2}$. Column capacity 20 meq.

linkage, and will be reported on later. The quantity of resin required for the column is suspended in distilled deionized water and poured into a pyrex tube $10 \mathrm{~mm}$ internal diameter to form a bed approximately $10 \mathrm{~cm}$ high. This is washed free of "fines" by passing water up through the bed. This also helps to remove air bubbles from the column which can cause channelling of the downward water flow and inefficient column operation. Pyrex glassware was used in all manipulations. The rate of flow of solutions through the resin was controlled by applying constant air pressure to the light-proof polythene bottles.

The collection efficiency of this resin has been measured using the $\mathrm{Ag}^{110} \mathrm{NO}_{3}$ at various aqueous dilutions. The $\mathrm{Ag}^{110}$ used has a specific activity of 0.1 curies per gram and a half-life of 253 days. The $\gamma$-emissions from this radio-isotope are principally of energies from 0.66 mev to $1.39 \mathrm{mev}$. The liquid samples containing this activity are placed in annular polythene containers of $10 \mathrm{ml}$ capacity. For counting purposes these containers are located on a $\mathrm{NaI}(\mathrm{Tl})$ scintillation crystal $1.7 \mathrm{~cm}$ in diameter and $2.5 \mathrm{~cm}$ in height, and the counting carried out with an electronic scaler. The counting efficiency of this unit is 6 per cent as determined with a standard 0.1 microcurie Caesium-137 annular source ( $\gamma$-energy $0.662 \mathrm{mev}$ ).

Using a column containing 30 milliequivalents of the resin and flow rates of 5 to $10 \mathrm{ml}$ per minute, the collection efficiency is between 92 and 97 per cent for all concentrations between $10^{-7}$ and $10^{-11} \mathrm{gm} \mathrm{ml}^{-1}$. In later experiments using smaller quantities of other types of resins, preliminary measurements have shown that the high efficiency can be maintained to $10^{-12}$ $\mathrm{gm} \mathrm{ml} l^{-1}$ and flow rates of $20 \mathrm{ml}$ per min.

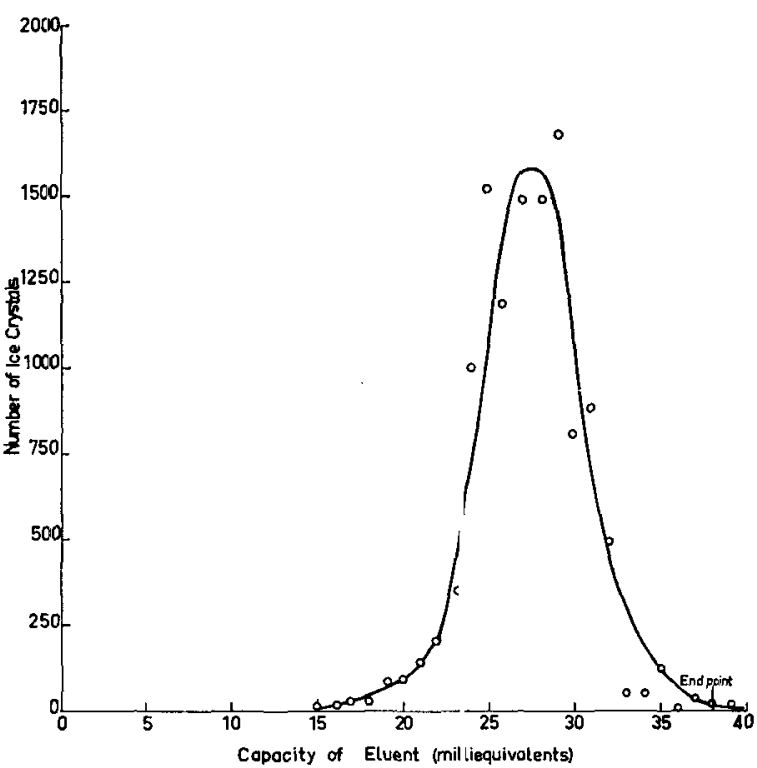

Fig. 2. Elution of $\mathrm{Ag}^{+}$with $0.05 \mathrm{M} \mathrm{Biz}\left(\mathrm{NO}_{3}\right)_{2}$. Column capacity $38 \mathrm{meq}$. Ice crystals produced from $0.04 \mathrm{ml}$ eluent samples sprayed into cold-chamber at $-15.0 \mathrm{C}$.

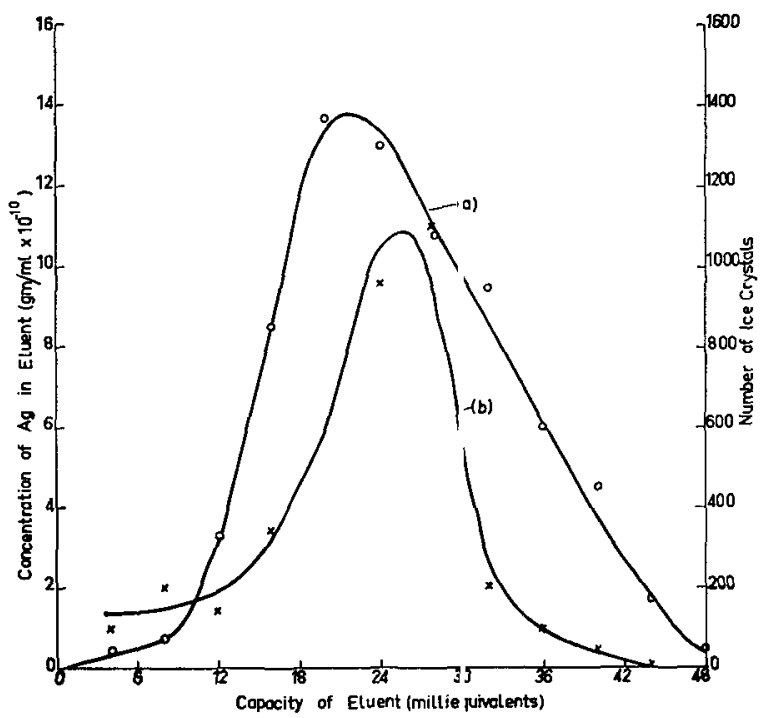

FIG. 3. Elution of $\mathrm{Ag}^{+110}$ with $0.2 \mathrm{M} \mathrm{Ba}\left(\mathrm{NO}_{3}\right)_{2}$. Column capacity 36 meq. Curve (a) shows concentration of $\mathrm{Ag}$ in eluent in $\mathrm{gm} \mathrm{ml}^{-1}$ $\times 10^{-10}$. Curve (b) shows number of ice crystals produced from $0.04 \mathrm{ml}$ samples of the same eluent sprayed into cold-chamber at $-15.0 \mathrm{C}$.

\section{Concentration and elution}

In general, divalent ions are more strongly held by the Amberlite resin so that they will force off the monovalent ions (the process of elution). The eluting solution used was $\mathrm{Ba}\left(\mathrm{NO}_{3}\right)_{2}$ at concentrations between 0.05 and 0.2 molar. The optimt $m$ concentrations and flow rates are still to be deternined for the different resins being considered. The elt tion has usually been carried out at $1-2 \mathrm{ml}$ per min. 
An illustration of the manner in which the elution takes place is given in Fig. 1. Approximately $10^{-4}$ milliequivalents of $\mathrm{Ag}^{110}\left(10^{-5} \mathrm{gm}\right)$ had been exchanged with some hydrogen ions on the resin. The $\mathrm{Ba}^{++}$will displace both $\mathrm{Ag}^{+}$and the $\mathrm{H}^{+}$ions remaining in the resin. Since nearly all of the resin is still in the hydrogen form, after exchange with the small amount of silver, the end point of the elution can be recognized by a change in $\mathrm{pH}$ value. The first eluents are highly acid and finally become about the same as the eluting $\mathrm{Ba}\left(\mathrm{NO}_{3}\right)_{2}$ solution, i.e., $\mathrm{pH}$ about 5 . It can be seen that the $\mathrm{Ag}^{110}$ comes off the column in the form of a chromatographic peak approximately 10 milliequivalents capacity from the end point. Each point on this graph represents the mass of silver in 20 milliliters of eluent, the $\gamma$-emissions being counted in the annular containers with the scintillation counter.

A similar result is shown in Fig. 2 where $4000 \mathrm{ml}$ of ordinary $\mathrm{AgNO}_{3}$ of concentration $10^{-10} \mathrm{gm} \mathrm{m}^{-1}$ has been passed through the resin column. The $\mathrm{Ag}^{+}$in this case was detected after elution with $0.05 \mathrm{M}$. Ba $\left(\mathrm{NO}_{3}\right)_{2}$ by a cold-chamber method as described in Section 4 below. Again we see the chromatographic peak at approximately 10 milliequivalents capacity of eluent from the end point. No appreciable amounts of silver have come off the column until 15 milliequivalents of eluent have passed through it.

Fig. 3 shows a case where both crystal counts and $\gamma$-counting were carried out on the one sample. On this occasion $4000 \mathrm{ml}$ of $\mathrm{Ag}^{110} \mathrm{NO}_{3}$ of concentration $1.5 \times 10^{-10}$ $\mathrm{gm} \mathrm{ml} \mathrm{m}^{-1}$ was passed through the resin. The collection efficiency of the column was measured as 92 per cent. The dimensions of the column in this case were practically identical with those used to obtain the results of Fig. 2, and again the crystal counts produced by the AgI first became evident after approximately 15 milliequivalents of eluent had passed through.

This form of spectral detection has been found to be possible using the elution with $\mathrm{Ba}\left(\mathrm{NO}_{3}\right)_{2}$ provided the total mass of silver on our particular columns is greater than about $10^{-7}$ gram. For these columns and a loading of $10^{-7}$ gram, only 20 per cent of the $\mathrm{Ag}^{+}$is at present recovered. If the loading is $10^{-6}$ gram, approximately 50 per cent is recovered. Some of the silver is lost to the walls of the containers used, but most of that not recovered is still held by the resin. The silver which is recovered is contained in a volume of 50 to $100 \mathrm{ml}$ of eluent being least when the molarity of the eluting fluid is highest. Other means of elution are under consideration. McNutt and Maier have reported high recovery yields using boiling $1 \mathrm{M} \mathrm{Na} \mathrm{Na}_{3}$ elution.

In summary then, these results indicate that from a sample of 15 liters of water in which the concentration of $\mathrm{Ag}^{+}$is $10^{-11} \mathrm{gm} \mathrm{ml}^{-1}$, a concentration of the silver by a factor of about 40 is at present achieved.

\section{Ice-crystal detection method}

The ice-crystal detection process is basically that which has been developed by Isono, some results from which were reported by him at the International Cloud Physics Conference in Australia (1962).

It has been pointed out by Isono that the solubility of $\mathrm{AgI}$ can be reduced from $3 \times 10^{-9} \mathrm{gm} \mathrm{m}^{-1}$ in pure water to approximately $3 \times 10^{-10} \mathrm{gm} \mathrm{ml}^{-1}$ in the presence of excess iodide ions of concentration $10^{-5}$ to $10^{-6} \mathrm{gm}$ $\mathrm{ml}^{-1}$. This means that provided the $\mathrm{AgI}$ is present in the sample to be studied in the cold-chamber at a concentration greater than $3 \times 10^{-10} \mathrm{gm} \mathrm{m}^{-1}$ the excess AgI will be in a colloidal form, and these colloidal particles will nucleate ice crystals in a supercooled fog. If the AgT is at a concentration less than this value, it will be in solution and it has been found that under these conditions no ice crystals are produced by the AgI, in the cold-chamber used, down to a temperature of $-16 \mathrm{C}$.

Hence, in the case of the rainwater samples, if there is AgI present above this critical concentration, addition of potassium iodide in the concentration stated will assist in the production or intensification of an AgI colloid and the AgI can then be detected directly as in Isono's case.

Rainwater samples so far collected in the seeding areas of Eastern Australia apparently have AgI in concentrations less than this critical value. The seeding aircraft dispense between 100 and $200 \mathrm{~g}$ of silver iodide per hour. If all of this came down uniformly in rain of intensity $5 \mathrm{~mm} \mathrm{hr}^{-1}$ over the target area of $1600 \mathrm{~km}^{2}$ the anticipated concentration of the silver iodide in the rainwater would be of the order of $10^{-11} \mathrm{gm} \mathrm{ml}^{-1}$.

We need therefore to concentrate the AgI until it can be brought up to at least the detectable limit. The detection sensitivity can be improved by ensuring as far as possible that large numbers of small colloidal particles form rather than small numbers of large ones. Adding the potassium iodide quickly at cool temperatures and stirring ultrasonically have all assisted in this respect.

During the elution, samples of $10 \mathrm{ml}$ of eluent are taken and $1 \mathrm{ml}$ of $\mathrm{KI}$ (concentration $10^{-4} \mathrm{gm} \mathrm{ml}^{-1}$ ) is added to each, stirring ultrasonically for a few minutes. A short length $(5 \mathrm{~cm})$ of $1 \mathrm{~mm}$ bore capillary tube is filled from this sample. These small samples of $0.04 \mathrm{ml}$ are then sprayed with a jet of dry nitrogen into a 10 liter capacity cold-chamber held at a temperature of $-15 \mathrm{C}$. These volume samples have been found to be convenient for the size of cold-chamber in use. This cold-chamber method therefore at present only allows for the use of about $1 / 100$ th of the solution available for analysis and it would appear that although the method has a very high sensitivity, other methods might be exploited which employ all of the available eluent. 


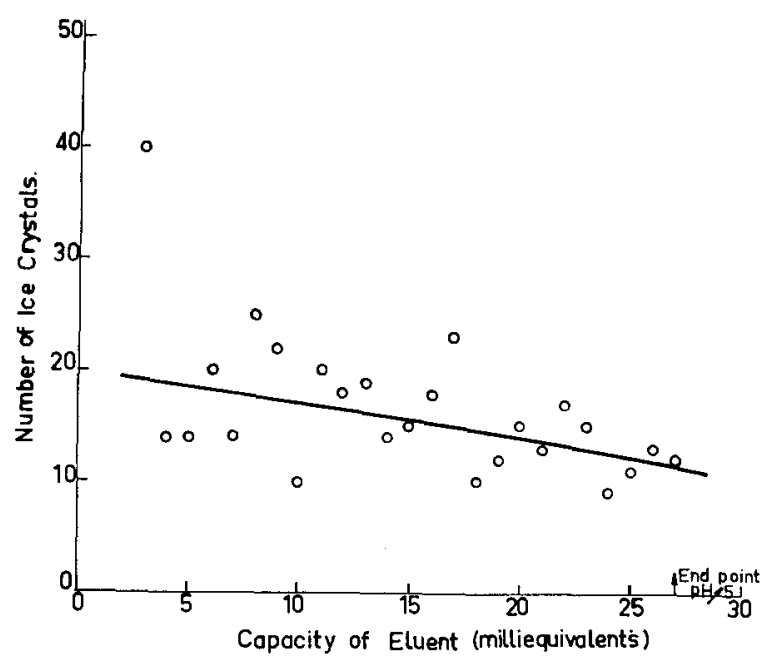

FIG. 4(a). Elution of unseeded rain sample, 2 February 1962 with $0.05 \mathrm{M} \mathrm{Ba}\left(\mathrm{NO}_{3}\right)_{2}$. Column capacity 27 meq. 15 liters of rainwater collected at station No. 2. Curve shows number of ice crystals from $0.04 \mathrm{ml}$ samples of eluent sprayed into cold-chamber at $-16.0 \mathrm{C}$. Result corresponds to concentration of $\mathrm{Ag}^{+}$in rainwater $<4 \times 10^{-12} \mathrm{gm} \mathrm{ml}^{-1}$.

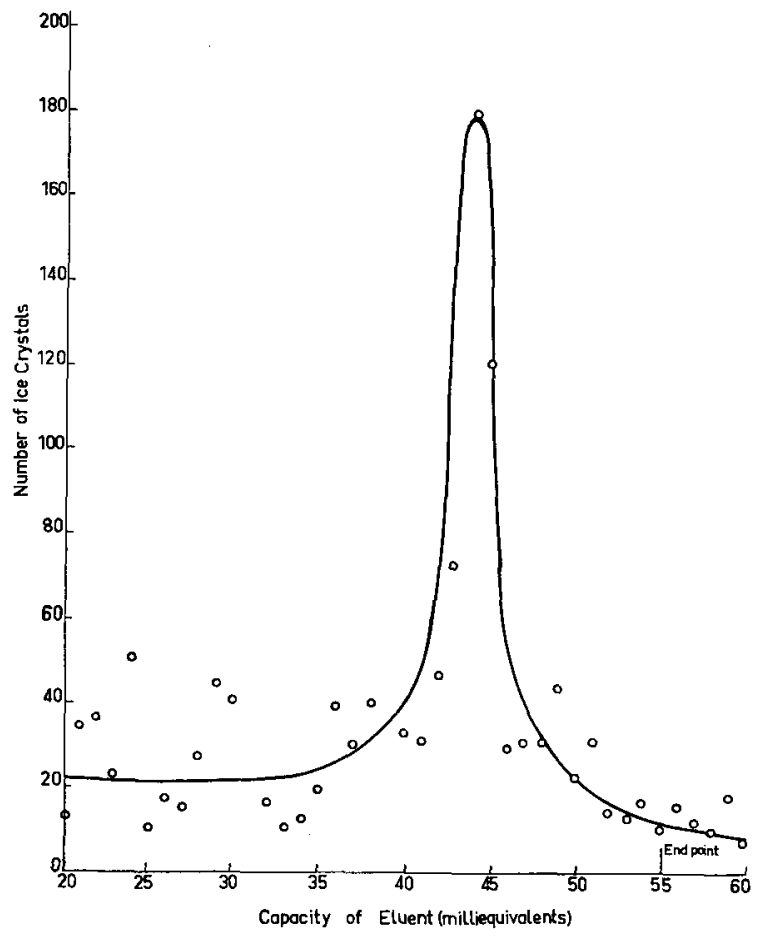

FIG. 4(b). Elution of seeded rain sample, 9 January 1962, with $0.05 \mathrm{M} \mathrm{Ba}\left(\mathrm{NO}_{3}\right)_{2}$. Column capacity $55 \mathrm{meq}$. 10 liters of rainwater collected at station No. 2. Curve shows number of ice crystals produced when $0.04 \mathrm{ml}$ samples of eluent are sprayed into coldchamber at $-16.0 \mathrm{C}$. Result corresponds to concentration of $\mathrm{Ag}^{+}$ in rainwater of approximately $10^{-11} \mathrm{gm} \mathrm{ml}^{-1}$.

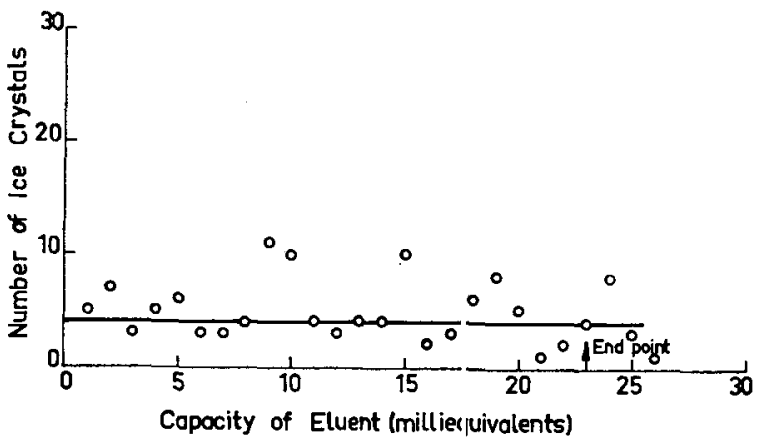

FIG. 4(c). Elution of unseeded rain sample, 24 July 1962, with $0.05 \mathrm{M} \mathrm{Ba}\left(\mathrm{NO}_{3}\right)_{2}$. Column capacity 23 ineq. Curve shows number of ice crystals produced when $0.04 \mathrm{ml}$ sanples of eluent are sprayed into cold-chamber at -13.0 C. 10 liters of rainwater collected at station No. 5. Result corresponds to concentration of $\mathrm{Ag}^{+}$in rainwater $<6 \times 10^{-12} \mathrm{gm} \mathrm{m}^{-1}$.

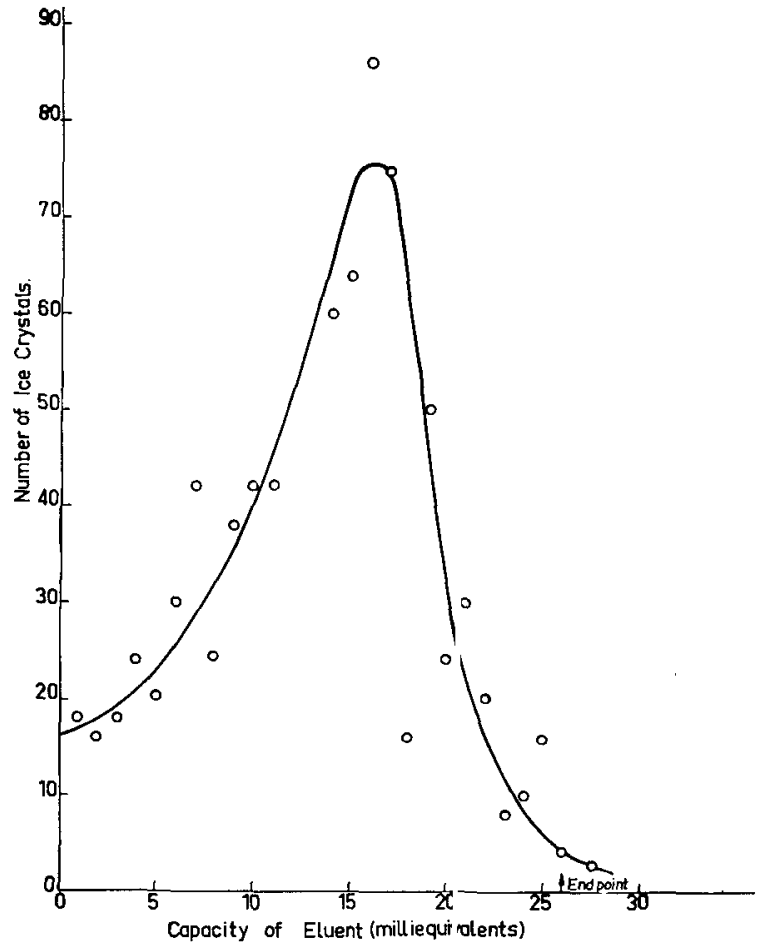

F1G. 4(d). Elution of seeded rain saraple, 13 August 1962, with $0.05 \mathrm{M} \mathrm{Ba}\left(\mathrm{NO}_{3}\right)_{2}$. Column capacity 26 meq. 13 liters of rainwater collected at station No. 5. Curve shcws number of ice crystals produced when $0.04 \mathrm{ml}$ samples of el ent are sprayed into coldchamber at $-14.0 \mathrm{C}$. Result corresponds to concentration of $\mathrm{Ag}^{+}$ in rainwater of approximately $10^{-11} \mathrm{gnı} \mathrm{ml}^{-1}$. 
When the samples are sprayed into the cold-chamber, ice crystals which form in the fog as a result of AgI being present as small colloidal particles fall into a tray of supercooled sugar solution (sp. gr. 1.23) where they grow to millimeter sizes and are counted. Before in jecting the sample the cold-chamber is first flushed with dry nitrogen and saturated with water vapor. This helps reduce the number of natural active nuclei which produce an ice crystal background. This background is usually no more than five crystals.

The concentration of the AgI is determined from the ice crystal counts by use of calibration methods in which standard solutions of $\mathrm{AgNO}_{3}$ and $\mathrm{Ag}^{10} \mathrm{NO}_{3}$ have been passed through the resin and, after elution, ice crystal counts and $\gamma$-counting effected simultaneously.

It can be seen from results such as Fig. 3 that the ice crystals are not detectable until the concentration of $\mathrm{AgI}$ in the sample sprayed into the cold-chamber is in excess of approximately $10^{-10} \mathrm{gm} \mathrm{ml}^{-1}$. However, it usually happens that before the peak in the elution curve, the background is higher than after the peak as illustrated in Fig. 3. This may be due to iodides of other insoluble salts of metals other than silver acting as freezing nuclei.

\section{Field observations}

Samples of rainwater have been collected from areas in which a seeding experiment is being conducted in the Warragamba catchment area of Eastern New South Wales. ${ }^{3}$ The water is collected from corrugated fiberglass roof surfaces in large polythene containers and

\footnotetext{
${ }^{3}$ Smith, E. J., E. E. Adderley and F. D. Bethwaite, 1962 : Cloud seeding experiment, Annual Report. Warragamba 1959-60 C.S.I.R.O., Radiophysics Laboratory Report RPL 156, 144 pp.
}

returned to the laboratory for analysis. These materials are used in an attempt to eliminate possible sources of contamination from metallic surfaces. The roofs are covered when not in use with polythene sheeting, and are of a size such that a 15 liter container is filled from $5 \mathrm{~mm}$ of rain. The polythene bottles are kept in lightproof polythene outer covers to minimize any ultraviolet effects on silver salts in the solution. As the collection points are located $200 \mathrm{~km}$ from the laboratory, 24 hours usually elapse before the sample is run through the ion-exchange column.

Preliminary results from two ordinary rain samples and two samples collected on days when the clouds have been seeded with AgI, are given in Figs. 4(a-d). Each of these curves represents the number of ice crystals obtained from a $0.04 \mathrm{ml}$ sample of successive $10 \mathrm{ml}$ volumes of eluent plotted against eluent capacity in milliequivalents.

The results obtained on days when seeding was carried out correspond to concentrations of ionized silver in the original rainfall of approximately $10^{-11}$ $\mathrm{gm} \mathrm{ml}^{-1}$ on the assumption that collection and elution efficiencies are as indicated by the $\mathrm{Ag}^{110}$ measurements. The other rain samples indicate that contamination with silver from atmospheric and other sources amounts to less than about $5 \times 10^{-12} \mathrm{gm} \mathrm{ml}^{-1}$.

\section{REFERENCES}

Bonner, O. D., and L. L. Smith, 1957: A selectivity scale for some divalent cations on Dowex 50. J. phys. Chem., 61, 1614-1617.

International Conference on Cloud Physics, 1962: U.G.G.I. Monograph No. 16, p. 75.

McNutt, N. S., and R. H. Maier, 1962: Microdetermination of silver using ion exchange concentration. Anal. Chem., 34, $276-278$. 